\title{
Teaching speaking in large classes: Crossing the barriers
}

\author{
NARGIS CHOWDHURY \& SABRINA M. SHAILA
}

\begin{abstract}
The modern theories, approaches and methodologies regarding classroom language learning perceive learning as an interactive process. In countries like Bangladesh, where English is a foreign language, one common phenomenon is that the teachers have to deal with large classes. This paper tries to focus on how the English language teachers deal with large classes at the tertiary level, especially when they are conducting classes to practice and evaluate speaking skills of students. A survey was conducted on 52 English language teachers working at different private universities to find out the problems teachers face when the carry on and observe speaking classes. The study finds that students' less exposure to the real life interaction in the target language, their nervousness, influence of the L1, adverse social environment along with other problems tend to hamper the smooth ongoing of the class. But as most of the teachers consider large class as a challenge rather than a problem, so they attempt to utilize different new methods of teaching speaking in classrooms. The authors of this paper suggest some innovative techniques and methods found to be effective and fruitful in large classes.
\end{abstract}

\section{Language Learning and Class size}

There is an ongoing debate regarding language learning/teaching and class size. Language teachers, all over the globe, may agree with the idea that there is an influential relationship between language instruction and class size. It is obvious that a large class demands special didactic attention compared to a small class. The research and study of Allwright (1989) in his article "Is Class Size a Problem?" aims to focus on the debate whether large class is a problem which may interfere successful learning.

In the developing countries like Bangladesh, India, Nepal, Pakistan etc. large class is a common phenomenon. Students, at the tertiary level, are enrolled to the 
English language courses (which are compulsory for everyone) and the class ultimately turns out to be a 'large class'.

\section{What is a Large Class?}

The concept of a large class is also a debatable issue, as Marcus (1997) in his article "Large Class Size: Strategies for Success" poses the question "how large is large?" regarding the class size. He also presented the ratio of language students in different countries which explicitly shows that the concept of large class varies from country to country. Marcus, for instance, shows that in USA the average large class size is 80, in India its 45, whereas in Hong Kong it is 16 and in Singapore it is 20.

As for Bangladesh, large class is a common scenario at the tertiary level. Bashir and Ferdousy (2006) in their study showed a very diverse picture concerning the number of students in the EFL classes. In their survey, conducted on a number of public and private universities of Bangladesh, they found that the number of students vary from 15 to 91 and $60 \%$ of the language instructor affirmed that this class size actually represents a large class.

\section{English Teaching and Learning in the Subcontinent}

English in the subcontinent has a history of over 200 years attached to it starting from the time the first British colonist settled in this area. Although the statement may be up for debate and controversy, but it has been stated that one of the very few benefits of colonial imperialism has been the gift of the common language which has persisted even after our former colonial rulers have left. English was considered to be one of the important assets for any native; be it for professional purpose or simply to belong to a higher social class. The situation doesn't seem to have changed much through the turn of century although more practical purpose and benefits have been added to the two previous causes. Needless to say English is now a determining factor in the job market, for immigration, overseas manpower export , IT sector, just to name a few. All these reasons have made academics and education policy makers realize the need to develop English skills at an early stage in an institutionalized form. The English (teaching approach as well as content) taught during the colonial rule aimed at creating a servant class; who would be 
suppressed into following the commands of the "Masters". Therefore the approach relied more on memorizing grammar and writing skills rather than speaking skills. Because speaking skills were more representative of interaction and exchange of ideas developing speaking skills were neglected. This trend seems to be continuing till date. As a result students who often do well in writing or reading get the lowest score in speaking skills.

\section{Speaking and Conversation Classes}

Speaking and conversation classes require extra care and attention from its instructor. In case of large class an inexperienced, new instructor may feel lost and confused and at first sight any speaking/conversation class may appear like a chaotic place. But speaking/conversation classes can turn out to be an amazing learning and teaching experience. In order to achieve success from these classes both the instructor and the students need to feel confident, positive, relaxed and to be cooperative with each other.

At the tertiary level most of the Bangladeshi universities (especially the private universities) include at least one speaking course in the syllabus or at least some speaking activities are integrated with the other English language courses. This importance given to the speaking activities is essential and vital for the students because most of them in their secondary and higher secondary level gain some competence in reading and writing, but many of them face difficulty to cope with the listening and speaking skills.

In-class speaking activity is something that requires instant feedback from the instructor because it is not permanent like a writing task and students tend to make more mistakes like 'slips of tongue' compared to the other skills. So, speaking/conversation classes require intense concentration of the teacher.

The most important thing is that most of the undergraduate level students in Bangladesh come from Bengali medium background where English is hardly used as the medium of instruction. So the students might be proficient in reading and writing, but they face difficulty in speaking. Even after studying English for 12 year in school and college they still lack proficiency and face problems to communicate 
in English. In order to make them competent and confident the speaking/conversation courses and activities are included in the syllabus.

\section{Research Methodology}

\section{The Survey and the Questionnaire}

A survey was conducted on 52 language teachers teaching in different private universities. The universities and the teachers were selected randomly for the survey. The private universities were particularly chosen for the study because in almost every private university there are some sorts of speaking courses or activities included in the language courses.

A questionnaire was circulated among the teachers. The questionnaire contains some fixed alternative and some open ended questions. The multiple choice and the fixed alternative questions were kept to verify and justify some of the presumptions of the authors. The open ended questions were kept to allow the participants to provide and share feedbacks. In this paper the authors have also shared some of their own opinions based on their experiences.

\section{The Participants}

The 52 participants were selected randomly from different private universities including Stamford University Bangladesh, United International University, East West University, BRAC University, American International University Bangladesh (AIUB), Eastern University, International Islamic University Chittagong, University of Science and Technology Chittagong, Independent University Bangladesh (IUB) and North South University located in Dhaka and Chittagong. Some of the participants have experiences in working in the public universities as well. The demographic information collected through the survey shows that among the participants 25 were male and 27 were female. Their age varies from 26 to 67 years and teaching experience from 1 to 34 years. Among the participants 2 are Associate Professors, 15 are Assistant Professors, 21 Senior Lecturers and 14 Lecturers. 


\section{Data Analysis Procedure}

After collecting the survey results the responses were counted in to percentage. In this qualitative research opinions and feedbacks of the respondents were given priority.

\section{The Class Size}

The survey shows that among 52, 40 teachers $(76.9 \%)$ have to take 3 to 6 language courses per trimester/ semester. 12 of them (23\%) take 1 to 3 courses. 37 respondents $(71.15 \%)$ said that the number of students in the class is more than 30 and the approximate number of students mentioned by them varies from 30 to 50 . All the 37 respondents agree that theirs is definitely a large class. In some universities the number of students increases and becomes more than 50 in the language courses because some senior students choose to do these elementary courses at a very late phase of their graduation. So facing large language classes is a common phenomenon for the teachers.

\section{Table 1}

\begin{tabular}{|l|c|c|c|c|c|c|}
\hline \multirow{2}{*}{$\begin{array}{l}\text { Q1: How } \\
\text { many } \\
\text { language } \\
\text { courses do } \\
\text { you take? }\end{array}$} & 12 & $23 \%$ & 40 & \multicolumn{2}{c|}{ b) Three to six } & \multicolumn{2}{c|}{ c) More than six } \\
\cline { 2 - 7 } & Number & Percentage & Number & Percentage & Number & Percentage \\
\cline { 2 - 7 } & & & & & 0 & $0 \%$ \\
\hline
\end{tabular}

\section{Speaking Skill and the Weakness of the Students}

In the questionnaire Question 5 aims to find out, according to the teachers in which skill the students are mostly weak. The result shows that $25 \%$ teachers think that students are most weak in writing and 19.2\% think they are weak in reading, whereas $32.6 \%$ think listening is a difficult task for their students and $42.3 \%$ teachers agree speaking is the Achilles' heel for their students. 
Table 2

\begin{tabular}{|c|c|c|c|c|c|c|c|c|}
\hline \multirow{3}{*}{$\begin{array}{l}\text { Q } 5 . \\
\text { Which } \\
\text { language } \\
\text { skill do } \\
\text { you think } \\
\text { students } \\
\text { are most } \\
\text { weak in? }\end{array}$} & \multicolumn{2}{|c|}{ a) Listening } & \multicolumn{2}{|c|}{ b) Speaking } & \multicolumn{2}{|c|}{ c) Reading } & \multicolumn{2}{|c|}{ d) Writing } \\
\hline & Response & $\%$ & Response & $\%$ & Response & $\%$ & Response & $\%$ \\
\hline & 17 & 32.6 & 22 & 42.3 & 10 & 19.2 & 13 & 25 \\
\hline
\end{tabular}

In response to Question 6, the teachers attempted to identify the reasons why the students are weak in particular skills. The following ideas mirror the reasons for weakness of the students in speaking skill:

a. Less exposure to the real life interaction: In their SSC and HSC levels, as there is hardly any scope for speaking practice, students at the tertiary level may feel confused about the real life interaction in English. Especially for the students of English literature, they might have good knowledge about the rich English used in literature, but to use everyday colloquial English they do not feel confident.

b. Less familiar with the features of spoken text, especially in terms of the cultural context of the language: In most of the cases the text books, audio and video tapes and other materials used for teaching speaking and listening in the classrooms do not represent the native culture. The situations and environments described and used in these materials are quite alien for the students. The market and the libraries are flooded by materials designed how to interact in the Western society and culture which is unfamiliar for the students. So a cultural gap is created between the spoken text and real life interaction. 
c. Influence of L1 (especially for those students who have come from outside Dhaka): In many of the schools and colleges in Bangladesh situated outside Dhaka (especially in the distant rural areas) English is not practiced much because of the lack of trained and experienced teachers. As a result, students coming from outside Dhaka (even students coming from Dhaka) lack fluency and have a tendency to code switch a lot while speaking.

d. Adverse social environment: One of the common problems in the large speaking classes is that when a student is speaking before the audience the classmates do not remain encouraging or friendly. They laugh at him/her, joke about his/her mistakes, talk among themselves, sometimes they do not even pay attention to what he/she is saying. This unfavorable environment created by the peers impacts the speaker deeply.

\section{Speaking-the Most Difficult Skill to Teach}

In response to Question 7 'Which skill do you find most difficult to teach in a large classroom?' 29 respondents (55.76\%) answered speaking. speaking is a skill that leaves no long lasting trace of its error (like writing) unless its recorded. Therefore, in a large class of 30-40 listening to every single student, correcting each of their mistakes and being prepared to prevent the recurrence of the errors are quite stressful and time consuming for any teacher. In response to Question 8, the teachers pointed out some of the major reasons why they consider teaching speaking is difficult to teach in a large classroom. The reasons are summed up here:

a. The influence of the traditional teaching methodology which discourages interactive class participation. Throughout their student life most of the students have gone through teacher dominated classes. They are accustomed with the traditional teaching methodology which discourages them from being interactive in class participation.

b. Mixed ability students of a large class: In mixed ability classes students having good command over English tend to dominate the class activities, 
whereas weaker, shy and introverted students try to maintain a low profile.

c. Nervousness of the shy and less interactive students of the class. In case of shy, less interactive students nervousness and stage fright may turn out to be fatal. Introvert, shy students show their hesitation and reluctance in speaking before the audience which hampers the natural spontaneous flow of speech.

\section{d. Some Other Problems}

- Less participation of the students;

- Maintain discipline becomes difficult;

- Space problem for both teacher and students;

- Physical discomfort;

- Intimidating atmosphere;

- Students tend to miss classes to avoid participation in activities;

- Giving individual attention becomes difficult for the teacher;

- Teacher's feedback is not proper enough and the teacher feels guilty;

- In the mixed ability classes it is difficult to solve all the problems.

\section{Time Pressure and Time Limitation Faced both by Teachers and Students}

In response to Question 9, 31 participants (59.6\%) said speaking is one of the most time consuming skills to teach. Question 11 tried to get the approximate duration of the language classes. 10 respondents said the class duration is from 30-60 minutes; 29 respondents said they get 60-90 minutes and 13 teachers said they get 90-120 minutes for each language class. Some of the universities do not offer any separate course for speaking; rather speaking is incorporated with other skills in the English language course. In such cases the teachers break down the time for teaching all the 4 skills. Here the teachers get lesser time for speaking compared to the full courses. On an average the class duration may vary from 50 to 90 minutes from university to 
university. But for a large class containing approximately 50 students this time is not enough. So, the time allotted for the students for practice and presentation is not enough. Because of time pressure students get even more nervous. On the teacher's side time constrain hampers his/her class observation and evaluation process.

\section{Large Class: Problem or Challenge?}

In response to Question 12, 'Large classrooms should be considered as a challenge rather than a problem' 34 participants $(65.3 \%)$ agreed that it should be taken as a challenge, whereas 16 teachers $(30.7 \%)$ consider it as a problem and 2 participants (3.8\%) remained neutral. In Bangladesh's context there is no other alternate way but to take large class as a challenge, because in a country like Bangladesh with the bulk of exploding population, the educational institutes are always under pressure to admit and accommodate the maximum possible number of students in the classrooms. In many cases it is not possible to divide the large classes into smaller ones. But teaching speaking requires special and individual attention and care. So the teachers, attempt to apply innovative methods and techniques by sorting out the classes into smaller segments to face the challenge.

\section{Table 3}

\begin{tabular}{|l|l|l|l|l|l|l|}
\hline $\begin{array}{l}\text { 12. "Large classrooms } \\
\text { should be considered as }\end{array}$ & \multicolumn{2}{|l|}{ Yes } & \multicolumn{2}{l|}{ No } & \multicolumn{2}{l|}{ Neutral } \\
\cline { 2 - 8 } $\begin{array}{l}\text { a challenge rather than a } \\
\text { problem" do you agree } \\
\text { with this? }\end{array}$ & Response & $\%$ & Response & $\%$ & Response & $\%$ \\
\cline { 2 - 8 } & 34 & 65.3 & 16 & 30.7 & 2 & 3.8 \\
\hline
\end{tabular}

\section{Methods and Techniques for Teaching Speaking}

Like the participants of the survey, the authors of this article take large speaking classes as challenge. A number of methods and techniques proved to be fruitful in teaching, evaluating and improving the skills of the students. Most of these 
methods are used worldwide which are altered and changed to fit the Bangladeshi culture and the classroom environment.

\section{Impromptu Speech}

This is an ice breaking method. Here every student of the class participates individually to deliver short speeches with very little and quick preparation. The instructor selects a list of topics; topics are written on cheats; cheats are randomly chosen by the students. In case of selecting topics the instructor should be aware of topics which are easy, interesting and known to the students; e.g. "The countries I wish to visit \& why?", "How to irritate the classmates during exams?" etc. Each student gets 10 minutes for preparation and 5 minutes for presentation. During the preparation time they brainstorm the topic. After each speech the instructor evaluates the speech especially concentrating on how well and promptly the students can speak their thoughts out in the target language and how quickly and simultaneously their thought process and speech work. The instructor also focuses on-

- the correct use of vocabulary,

- correct pronunciation, and

- accent

Grammatical errors can be given secondary priority. While one student is speaking, the rest of the class can take note of the new words and verbal expressions used by him/her.

\section{Simulation}

This is a group assignment. The entire class is divided into several groups. Group members may vary from 2 to5; it should not be more than that because equal participation of every student is required here. Unlike impromptu speech, students have enough time for preparation and doing home work. Each group chooses a particular situation, like, ordering foods in a restaurant, a journalist interviewing a celebrity; participating in a TV talk show etc. they have 10 minutes to perform. The issues evaluated for this task are- 
- The correct use of vocabulary at appropriate situation

- The appropriate use of grammatical structure and verbal expressions, and

- $\quad$ Correct pronunciation

If possible the activities can be recorded or videotaped. Later, in the next class it can be shown to the students and the students would try to identify their own mistakes.

\section{Simulating the Role of a Counselor (The "Dear Abbey Approach")}

This is a pair activity. The instructor will select a number of mails usually published in the newspapers or magazines in which people usually write about their personal problems (like marital or love problems) to the social counselors. The class is divided in to a number of pairs. Each pair is given a problem. They are given 10 minutes to study and solve the problem. After 10 minutes, in front of the audience one student summarizes the problem and his/her partner gives suggestions or solutions to the problem.

\section{Job Interview}

This is a group simulation. Students divide themselves in groups (number of group members minimum 2 maximum 5). First they need to choose a particular field appropriate for the English graduates (e.g. teaching, journalism, banking, development field etc.). Students need to do some study before hand on issues like what sort of questions are usually asked in the interview board, how to answer them. They also need to have ideas about appropriate dress up, get up, manners, posture, and gesture. Their simulation time is 10 minutes. Some of the students play the roles of employer and some as employees. In the feedback session the instructor concentrates on correct usage of language (i.e. vocabulary, grammar, pronunciation etc.). Manner and etiquette are also evaluated but the main focus is on language.

This activity can also be recorded and shown to the students so that they can identify their flaws. 


\section{Linked Story Telling}

This can also be an ice breaking method in the first class. Usually the instructor takes the initiative by narrating a story or describing a scenario. Then a student continues with the story. He/she speaks for about 2 minutes and takes the story to a certain point. Then a student sitting next continues from the point where the first student stopped. In this way every individual speaks for at least 2 minutes and together they construct a whole story. Students enjoy this very much as it usually turns out to be very funny and hilarious.

\section{Using Movie Clips}

In this technique the students will be divided into pairs or in small groups. Each group will be shown a movie clip with inconclusive ending. The groups will try to guess what could happen next.

Sometimes they are shown a particular scene, e.g. the war scene from the movie 300. They will describe the scenes and the other students will take note of the words to describe that scene. This would help them to increase vocabulary.

\section{Picture Presentation}

This is a semi-formal presentation where students will have to use multimedia, power point or any other visual aid. In this task each student chooses a picture which can be a photograph or painting. It can be a famous photograph published in any newspaper/magazine or web page; it can be a famous painting like the Last Supper, or it can be any picture or painting carrying special significance for the student. The student may explain the picture, or he/she may talk about why this picture is so special for him/her or he/she can narrate if there is any story behind it.

\section{Classroom Debate}

The teacher will present a list on debatable topic related to society, politics, moral issues etc. there will be several groups in the class; each group will have 2/3 members (not more than that). The teacher will explain the significance of the topics 
first. Then the groups will choose topics. Next there will be some pairs of groupsone will support and the other will oppose the topic. Each group will get 10 minutes to prepare argument. Each member from each group will present argument for two minutes. After all the members have spoken each group will have two minutes to prepare a rebuttal or refutation. The group members will choose a leader who will present the rebuttal for one minute.

In the entire debate procedure the teacher acts as a moderator who will announce the winner at the end. In order maintain discipline in the class the instructor should employ some rules prepared beforehand.

\section{Listening Practice}

Speaking classes remain incomplete without listening tasks. There are numbers of listening task that can be practiced in a speaking/conversation class. Two methods are discussed here:

a. The students will listen to some recorded English conversations where English is used in the Received Pronunciation (RP). After listening to each part they will be asked questions by the instructor which they will answer orally.

b. Listening to English songs and trying to understand its lyrics can be a good practice. In this technique the teacher distributes some handouts to the students containing the lyric of a particular some. A certain places some particular words will be missing. The song will be played and while listening to the song the students will try to fill up the gaps in the lyric. If needed the song will be played twice but not more than that. The teachers can first start with the American county songs containing clear and easy lyrics.

\section{Points of Concern}

Teachers should pay special attention to the following issues while practicing speaking in large classes. 
1. Teachers have to make sure that all students participate in the speaking practice as well as the inter exchange in the classroom.

2. There should be even and equal contribution by all the students in the speaking process. The teacher should take care that the discussion is not dominated by some specific students or group.

3. Speaking is one of the most time consuming skills to teach and practice. It requires interaction and interchange between each individual student and teacher. Unfortunately the biggest challenge to this process in a large classroom is the time limitation which constraints the teacher to limited and often inadequate interactive practice. To solve this teacher should maintain a consistent turn taking and also carry over the practice in the next class. Therefore the practice in the next class will begin with those who have not participated in the previous class.

4. There should be regular practice sessions which will maintain the flow and level of the students.

5. Maintaining a balance in the performance gap is also another area that teachers should be concerned about.

6. In a large mixed ability class there will always be some students who are shyer than the rest at speaking out and expressing their views. The teacher has to draw out responses from the shyer and less participatory students and develop their confidence.

7. Although teachers should pay equal attention to all the students but there are also some time when discrimination is necessary. This is one kind of positive discrimination when the teacher will focus more time and attention to the weaker and less participatory students of the class.

\section{Conclusion}

The difficulties and problems faced by a language teacher in observing and evaluating a large speaking class are undoubtedly painstaking. In order to convert 
the difficulties into challenges the teacher needs to be focused on students' needs. $\mathrm{He} / \mathrm{she}$ needs to have an open mind to be innovative to help the students to attain success regarding speaking. More and more modern approaches and methods

should be introduced. Ultimately the experiences gathered from these classes become an invaluable asset for a language teacher.

\section{Works Cited}

Allwright, D. (1989). Is class size a problem? Lancaster-Leeds Language Learning in Large Classes Research Project Report No. 3. Retrieved from http://www.eric.ed.gov/PDFS/ED322754.pdf.

Bashir, A., \& Ferdousy, S. (2006). “Problems and strategies of teaching English in large classes at universities in Bangladesh." Stamford journal of English, 2, 38-52.

Marcus, S (1997). “Large class size: Strategies for success.” The English teacher, 26. Retrieved from http://www.melta.org.my/ET/1997/main6.html.

\section{References}

Klippel, F. (1984). Keep talking: Communicative fluency activities for language teaching. Cambridge: Cambridge University Press.

LoCastro, V. (2001). “Large classes and student learning.” TESOL Quarterly, 35, 493-96.

Sarwar, Z. (2001). “Innovations in large classes in Pakistan." TESOL Quarterly, 35 (3), 497-500. 


\section{Appendix}

\section{Teaching speaking in large classes: Crossing the barriers}

This questionnaire is designed to conduct a research on "Teaching Speaking in Large Classes: Crossing the Barriers". The major objectives of this research are to investigate how the English language teachers deal with the large classes at the tertiary level, especially when they are conducting speaking skills of students. This paper also tries to find out what problems the teachers face when they carry on and observe speaking classes, how they try to solve the problems and how they utilize different new methods of teaching speaking in the language classrooms while dealing with these problems. Therefore your kind cooperation is needed for successful completion of this research.

Please complete the following questions to reflect your opinion as accurately as possible. Please put a tick mark on your answer or write down your opinion. The data collected through this survey will be kept strictly confidential and will be used for the academic research only.

Thank you very much for your time and opinion!

\section{Demographic Information:}

Name of the University:

Job Title:

Years of teaching experience:

Sex: Male Female

Age:

\section{Questionnaire}

\section{How many language courses do you take?}
a) One to three
b) Three to six
c) More than six 
2. How many students do you usually have in a language course?
a) Less than fifteen
b) from fifteen to thirty
c) More than thirty

3. If the answer to your above question is "c) more than thirty" please specify the number of students in the course.

4. Do you consider your language class room to be large?
a) Yes
b) No
c) Neutral

5. Which language skill do you think students are most weak in?
a) Listening
b) Speaking
c) Reading
d) Writing

6. Please state three reasons why you think students are weak in that particular skill.
a)
b)
c)

7. Which skill do you find most difficult to teach in a large class room?
a) Listening
b) Speaking
c) Reading
d) Writing

8. Please state three reasons why you consider the particular skill difficult to teach in a large classroom.
a)
b)
c) 
9. Which language skill is most time consuming to teach?
a) Listening
b) Speaking
c) Reading
d) Writing

10. Please state three reasons why you consider that particular skill to be time consuming.
a)
b)
c)

11. What is the duration of the language classes?
a) 30- 60 minutes
b) 60 - 90 minutes
c) 90 - 120 minutes d) more than 120 minutes

12. "Large classrooms should be considered as a challenge rather than a problem" do you agree with this?
a) Yes
b) No
c) Neutral

Thank you! 